\title{
EL VALOR DE LA GUERRA Y LA PAZ EN EL PENSAMIENTO FENOMENOLÓGICO DE MAX SCHELER
}

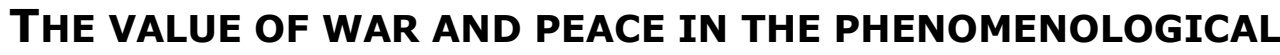 \\ THINKING OF MAX SCHELER
}

\author{
Marisol Ramírez Patiño \\ Universidad de Veracruz \\ cirano.filosofia@gmail.com
}

\begin{abstract}
Resumen: El problema de la paz ha interesado y preocupado a la conciencia universal prácticamente desde sus inicios. No obstante, la historia que nos es conocida se caracteriza por una larga sucesión de conflictos armados que no han traído ni siquiera los atisbos indubitables de su consecución. Así, entre el ecuménico anhelo de la paz y la adversa realidad, preguntamos: ¿es la idea de la paz humanamente posible? Este ensayo aporta una respuesta a esta interrogante desde las reflexiones de Max Scheler (1874-1928). Los dos escritos que muestran con más detalle su postura ante esta problemática, Der Genius des Krieges und der Deustche Krieg (1915) y Die Idee des ewigen Friedens und der Pazifismus (1927), respectivamente, ofrecen elementos que podrían concretar la experiencia actual de la guerra, así como la posibilidad de un rotundo estado de paz en el mundo.
\end{abstract}

Palabras clave: Pacifismo, guerra, cultura, espíritu, amor.

\begin{abstract}
The problem of peace has interested and concerned to the universal consciousness since its beginnings. However the known history is characterized by a large succession of armed conflicts that hasn't even brought blinks of its uncontested triumph. Thus, between the ecumenical craving for peace and the opposite reality, we ask: Is it the idea of peace humanly possible? This essay tries to give an answer on this questions from the reflections of Max Scheler (19741928). Both writings that show with more detail his position to this problem, Der Genius des Krieges und der Deustche Krieg (1915) y Die Idee des ewigen Friedens und der Pazifismus (1927) respectively, they both offer elements that could grasp the actual experience of war, as well as the possibility of an absolute state of peace in the world.
\end{abstract}

Keywords: Pacifism, war, culture, spirit, love.

\section{INTRODUCCIÓN}

En 1915, cuando la Primera Guerra Mundial estaba en su punto más álgido, Scheler escribe El genio de la guerra y la guerra alemana un prolífico, aunque polémico ensayo, en el cual se aborda el fenómeno de la guerra en general y su relación con el porvenir cultural y espiritual de Europa. El escrito surge en medio de un estado de neurosis intelectual de la guerra, que había llevado a escritores y académicos en casi todos los países europeos a responder al llamado de su nación e implicarse activamente en el conflicto, ya sea directamente en los 
frentes de batalla, o bien, a través de la formación de frentes literarios, cuyas ideas - generalmente cargadas de una patriotería exaltada y agresiva junto al sentimiento de unidad nacional - se articularon en los principales diarios, semanarios y revistas nacionales con el fin de defender y legitimar las decisiones belicistas a uno y otro lado del Rin. Scheler también respondió al ineludible deber de servir a la nación con la pluma e imbuido por el júbilo y el fervor patriótico compartido entre la energía heroica de las masas, tal y como él mismo admite desde las primeras páginas de su obra (Scheler, 1915) ${ }^{1}$, esbozó algunas de las típicas e infames expresiones de la ideología nacionalista para justificar a Alemania en su agresión, a la vez que desestimaba la paz y daba la bienvenida a la guerra como una forma de renovación espiritual, creando así la impresión comprensible de que el fenomenólogo glorificaba la guerra y que era un imperialista alemán de la peor especie.

No obstante, a medida que el conflicto se prolongaba y mostraba su verdadero rostro de muerte y destrucción, apagando las brasas de aquellos discursos nacionalistas ya lejanos y sumiendo a toda Europa en el más oscuro pesimismo, Scheler comenzó a enemistarse con la guerra, y más tarde afirmó - tras una estancia durante la Pascua de 1916 en la abadía benedictina de Beuron- que sólo podía haber un futuro tras las grandes batallas entre los pueblos mediante un profundo acto de arrepentimiento colectivo que fuese capaz de provocar una autentica renovación cultural y social fundada bajo los ideales del amor, la compresión y la paz, lo cual sólo le parecía posible en la personificación de la idea cristiana de la comunidad tal como viene dada por la iglesia católica. Doce años después, con la amenaza cada vez mayor de una segunda, y mucho más violenta, guerra mundial, Scheler se dirige ante el Ministerio de Guerra alemán en Berlín para exponer su ensayo titulado: La idea de la paz perpetua y el pacifismo (2000), en donde contempla la consecución de la paz perpetua como real y posible, siendo éste el desafío profético para nuestra época.

En lo que sigue, nos referiremos a la interpretación filosófica de Scheler sobre la guerra y la paz, limitándonos a sus argumentos implicados en la evaluación y

\footnotetext{
1 "Me temo que el movimiento apasionante del espíritu del cual nació este libro - cuántas veces he tenido que dejar de lado la pluma al verme cautivo entre sus páginas - me ha llevado a juzgar a personas y pueblos más allá de los límites de lo permitido. Si es el caso, les pido a los afectados perdonen mi estrechez de miras" (1915: 14, traducción propia).
} 
comprensión de ambos fenómenos. Scheler es quizá mejor conocido por sus trabajos en torno a la persona y el amor, y, por lo general, los estudiosos de su obra suelen pasar por encima de sus publicaciones en torno a la guerra (especialmente aquéllas en donde la ensalza). Sin embargo, creemos que estos escritos son valiosos no sólo desde la continuidad doctrinal del autor, sino también porque representan un esfuerzo por comprender y dar solución a los problemas del presente desde una perspectiva filosófica.

\section{EL VALOR DE LA GUERRA}

Contrario a lo que pudiese pensarse, Max Scheler no estuvo sólo en la interpretación positiva de la guerra, antes bien, se puso de pie en el contexto de un sentimiento belicista compartido por todas las naciones, y que, particularmente en Alemania, había adquirido un matiz antiliberal, antidemocrático y anti-occidental $^{2}$. De hecho, si revisamos otros escritos populares de Scheler anteriores a la publicación de El genio de la guerra y la guerra alemana en 1915, es posible advertir también en ellos la más fina expresión del ethos alemán imperante en aquel entonces. Por ejemplo, en la primera versión de su manuscrito titulado Modelos y líderes (1912-1914) Scheler (1957) ${ }^{3}$ concibe la figura del héroe -junto con la del genio y el santo- como un modelo, es decir, como la encarnación personal de una estructura de valores y también como uno de los motores de la

\footnotetext{
2 Una muestra de lo anterior quedó ejemplarmente plasmada el 4 de octubre de 1914 en el Manifiesto al mundo civilizado (Aufruf an die Kulturwelt), dirigido por un grupo de 93 prestigiosas figuras alemanas incluyendo a varios ganadores del Premio Nobel como el químico A. Baeyer, el físico M. Planck y el filósofo R. Eucken (este último, por cierto, mentor en la juventud intelectual de Max Scheler). El manifiesto se erigió como una declaración moral de guerra que pretendía, por un lado, apoyar y justificar las acciones ofensivas del ejército alemán y, por el otro, defender y afirmar lo que les parecía un bien universal a saber, su cultura, ante la amenaza de ser absorbida por la civilización occidental. En efecto, el escrito concibe a Alemania como un país que ha luchado por mantener la paz y que no se ha levantado "hasta que no ha sido amenazado y después atacado a traición por tres grandes potencias". ${ }^{2}$ Asimismo, el texto sugiere que la guerra contra el Reich no era solamente contra el militarismo alemán, tal como lo sostenía la propaganda extranjera, sino que se trataba en el fondo de una guerra en contra de la propia cultura alemana. El manuscrito revela, además, que el militarismo es un elemento indisociable de la cultura alemana, nacido en pos de su defensa y que, de no haberse contado con él "ésta ya habría desaparecido de la faz de la tierra". ${ }^{2}$ Por último, el manifiesto hace alusión a la distinción entre la comunidad (Gemeinschaft) y sociedad (Gesellschaft) al afirmar que "el ejército alemán y el pueblo alemán no son sino uno y este sentimiento une fraternalmente a 70 millones de alemanes sin distinción de cultura, clase o partido". UngernSternberg, Jürguen von, Das Manifest der 93 un die Anfänge der Kriegspropaganda im Ersten Weltkrieg, Stuttgart: Steiner, 1996, p. 156. (Traducción propia).

${ }^{3}$ Scheler, Max, Vorbilder und Führer en Gesammelte Werke, Bd. X: Schriften aus dem Nachlass. Bd. 1: Zur Ethik und Erkenntnislehre, Bern: Francke-Bouvier Verlag, 1957, pp. 255-318. El santo, el genio, el héroe, Buenos Aires: Nova, 1961.
} 
historia. Inspirado en el ideal romántico del griego que impulsara el romanticismo alemán, el héroe scheleriano es "el intrépido que tiende hacia lo desconocido y gana allí un nuevo terreno para la vida" (Scheler, 1961: 135). Militar, colonizador y estadista son los principales tipos de héroe, siendo este último el verdadero artífice de la política, pues, citando al alemán: "eleva a su Estado activamente a un grado superior de su desarrollo, superior a la que poseía, responsable ante sí, pero sabiéndose y sintiéndose responsable con los otros para la totalidad del Estado y de sus conciudadanos" (Scheler, 1961: 136). Empero, para lograr lo anterior, éste siempre ha de estar respaldado de una cultura espiritual superior y de una conciencia religiosa:

Junto a la apasionada voluntad de poder [propio de la naturaleza del héroe], el hombre de Estado debe tener una idea concreta de valor y un fin concreto; el programa no es más que un medio para ese fin. Las ideas generales de valor, el político las obtiene de la cultura espiritual, sobre todo el genio de su país, eventualmente de la inspiración religiosa. Sin estas ideas de valor, la política estaría vacía (Scheler, 1961: 137).

Así, de carácter audaz, intrépido y bondadoso, dispuesto al sacrificio por los amigos y por la comunidad, no es de extrañar que Scheler tuviese en muy alta estima la figura del héroe, al punto de haber designado a personalidades tales como Napoleón, Federico el Grande y Bismarck como las formas más insignes del heroísmo activo, al mismo tiempo que dedicara su disertación sobre el genio de la guerra, precisamente, a cada uno de esos héroes individuales, a quienes llamó fraternalmente sus amigos en el campo, no sólo como una muestra de solidaridad, sino también de admiración a su sacrificio.

Por otra parte, El resentimiento en la moral (Scheler, 1938$)^{4}$ es otro de los textos en donde puede apreciarse la resistencia por parte del autor hacia el ideal de una civilización esencialmente "utilitaria" proveniente del mundo franco-anglosajón. A primera vista, el escrito se presenta como una réplica a la concepción nietzscheana de que la moral cristiana y, en particular, el amor cristiano, tenían su origen en el resentimiento (Nietzsche, 1995). Sin embargo, al adentrarnos en

${ }^{4}$ Scheler, Max, Das Ressentiment im Aufbau der Moralen en Gesammelte Werke, Bd. III: Vom Umsturz der Werte. Abhandlungen und Aufsätze, Bonn: Francke-Bern: Francke-Bouvier 1955, pp. 33-148. El resentimiento en la moral. Traducido por José Gaos. Buenos Aires: Espasa-Calpe, 1938. 
el texto nos encontramos con la acusación de Scheler hacia la moral moderna burguesa por haber subordinado, mediante la inversión del orden jerárquico, los valores vitales a lo útil, relativizando así toda la vida a su valor de uso. Scheler concibe el resentimiento como una de las formas más generales de la destrucción y trastorno del ordo amoris (Scheler, 2008) ( $^{5}$ que impele a la persona en contra de su propia naturaleza hacia un movimiento de profundo odio. Este acto es generado a partir de un engaño estimativo, una ilusión del preferir nacida de la confusión de los propios intereses con el contenido del conocimiento objetivo de los valores, que consiste en tomar algo por valioso de un modo positivo porque se da en una tendencia $y$, a la inversa, asignarle un sentido negativo porque es dado en una contratendencia. En consecuencia, tal engaño provoca la sobreestimación de aquellos valores inscritos en una tendencia positiva y, por lo contrario, en la subestimación de los valores que también son sentidos, pero para los cuales la persona se sabe incapaz de realizarlos. Para Scheler, la moral burguesa, bajo la forma de una "filantropía moderna", incurriría en este engaño estimativo debido a que no tiene como fundamento último el amor (como la moral cristiana), sino la promoción del bien común, derivada de los instintos de conservación. De ahí, que la filantropía, rebajándose a sí misma hasta convertirse en un valor meramente técnico para el bienestar general, aprecie los valores de un modo invertido, pues, a cualquier placer sensible -independiente del valor de la persona que goza tal placer - subordina el valor excelso del amor y la dicha enlazada con el acto de amor. Scheler concluye diciendo que no es el cristianismo, sino el movimiento de la filantropía moderna el que se encuentra fundado en el resentimiento: "es un contraimpulso contra las minorías dominantes en posesión de los valores dominantes, la humanidad es meramente un pretexto esgrimido contra el objeto odiado. La filantropía es la expresión de una reprimida repulsa frente a Dios" (1938: 146).

Ahora bien, en El genio de la guerra y la guerra alemana, Scheler no está realmente interesado en explicar los orígenes políticos de la guerra, sus razones

\footnotetext{
${ }^{5}$ Scheler define al ordo amoris en otro lugar como «la sencilla estructura de los fines más elementales que se propone, al actuar, el núcleo de una persona, la fórmula moral fundamental según la cual existe y vive moralmente este sujeto». Cf. Scheler, Max. Ordo Amoris. Traducido por Xavier Zubiri. Madrid: Caparrós, 2008: 23.
} 
o múltiples motivaciones; tampoco pretende juzgar a la bondad o maldad de este conflicto en particular. Su objetivo primordial -el cual trasciende a lo meramente propagandístico para colocarse como una emanación directa de su filosofía- es captar a la guerra en su esencia. Siguiendo la dirección del método fenomenológico $^{6}$, nuestro autor emprende una escrupulosa descripción que le permite intuir - ver - intelectualmente la estructura significativa interna del acto bélico, libre de todo presupuesto que, en este caso, provenía principalmente de la moderna biología mecanicista, a la cual acusa de difundir una concepción errónea de la vida $y$, consecuentemente, de la guerra.

En efecto, Scheler contempla el fenómeno bélico como una expresión del dinamismo de la "vida" (Leben). El muniqués no piensa esta noción en términos de la biología, sino en los de la "filosofía de la vida" (Lebensphilosophie): "vivir es producción, creación de multiplicidad organizada, aumento, expansión, dominio" (Ortega y Gasset, 1963: 127). Por tal motivo se opone a la doctrina evolucionista que proclamó Darwin $(1997)^{7}$, la cual posteriormente traspuso Spencer

\footnotetext{
${ }^{6}$ Se ha discutido el impacto que tuvo la fenomenología para el desenvolvimiento intelectual de Max Scheler, quien para 1902 (año en que conoció a Husserl y sus Investigaciones lógicas) ya tenía su formación filosófica primera completada, así como la orientación de su investigación sobre el hombre y las manifestaciones del espíritu humano. Sin embargo, el contacto con la fenomenología marcó, ciertamente, un punto de transición entre la posición neokantiana que Scheler tenía en ese momento hacia su pensamiento más maduro. A propósito, Henckmann propone un doble comienzo en la filosofía de Scheler: El primero, de tipo conceptual, refiere a su periodo en Jena, influenciado principalmente por Eucken y Bergson. El segundo, de tipo más bien metodológico, es situado también en Jena, aunque luego de su encuentro con Husserl, efectuando en adelante un análisis proto-fenomenológico para la resolución de diferentes problemas (Cf. Christian Bermes, Wolfhart Henckmann, Heinz Leonardy, Denken des Ursprungs-Ursprung des Denkens. Schelers Philosophie und ihre Anfänge in Jena, Würzburg: Königshausen und Neumann," 1998: 11-32). En vista de lo anterior ha de considerarse, por lo tanto, que la influencia efectiva de la fenomenología no puede retrotraerse en Scheler más allá de 1906, cuando en la primera edición de las Investigaciones lógicas se describía a este saber como una psicología descriptiva: "La necesidad de una fundamentación psicológica de la lógica pura de un tipo estrictamente descriptivo, indica la mutua independencia de ambas ciencias, la lógica y la psicología. Esto es así porque una pura descripción es meramente un estadio de inicio de la teoría, pero no la teoría en sí misma. De este modo una misma descripción pura puede usarse como preparación para muy distintas ciencias teóricas" (Hua, XIX, 24). Aunque, ya para la segunda edición ni este pasaje ni el término "psicología descriptiva" aparecen. Es más, Husserl afirma en ella que la Fenomenología no es psicología descriptiva, y Scheler continuó entendiendo de este modo a la fenomenología, tal y como se muestra en algunos textos redactados en la misma época, por ejemplo en la observación preliminar de El resentimiento en la moral: "una cosa es descomponer mentalmente el mundo de la percepción interna en complejos y éstos a su vez en últimos elementos 'simples', investigando las condiciones y las consecuencias de los complejos modificados artificialmente (mediante la observación y el experimento), y otra cosa es describir y comprender las unidades de vivencia y de sentido, que están contenidas en la vida misma de los hombres, sin ser producidas por una 'síntesis' y un 'análisis' artificiales. Aquél es el camino de la Psicología sintético-constructiva y explicativa (orientada metódicamente en la ciencia natural); éste es el camino de la Psicología analítico-comprensiva y descriptiva", Scheler, Max, El resentimiento en la moral, Buenos Aires: Espasa-Calpe, 1938: 7.

7 "Debido a esta lucha [por la existencia], las variaciones, por ligeras que sean y cualquiera que sea la causa de que procedan, si son en algún grado provechosas a los individuos de una especie en sus relaciones infinitamente complejas con otros seres orgánicos y con sus condiciones físicas de vida, tenderán a la conservación de estos individuos y serán, en general, heredadas por la descendencia. [...] Este principio, por el cual toda ligera variación, si es útil, se conserva, lo he denominado yo con el término de
} 
a la moral y la sociología, por haber incurrido en una falsificación de la vida, debido a que sustrae su dinamismo originario y lo sustituye con algo secundario y adjetivo, a saber, mera adaptación por una tendencia hacia la propia conservación: "este concepto es decididamente individualista, pasivo y mecanicista" (Scheler, 1915: 37). Así, al reducir a la vida a un principio estático e impasible, la única interpretación posible de la guerra sería, de acuerdo con el propio Scheler: "un medio imprescindible para la selección del género humano y de determinadas razas y élites dirigentes; un medio para la «selección de pueblos y de grupos», subordinándola a los conceptos de «selección natural» y de «lucha por la existencia»" (Scheler, 2000: 141). Pero en la guerra no basta solamente el motivo de la propia conservación; también se lucha por valores superiores a los utilitarios, como el poder, la gloria o el honor, y esto ocurre así porque el hombre, aunque está sujeto enteramente a las leyes naturales como el ser vivo que es, se define por su capacidad de trascendencia sobre la vida misma. Esa capacidad de trascendencia es el "espíritu" (Geist). Marcos Suances nos da una mayor claridad a lo planteado:

Vida y espíritu no sólo son dos realidades irreductibles, sino diferentes, que pertenecen a dos esferas distintas del ser con leyes propias. En cuanto ser vivo, el hombre es un microcosmos que incluye todos los grados alcanzados por la evolución de la vida. Pero es un microcosmos espiritual o persona en que la esfera vital queda trascendida por un ámbito superior de valores que realiza el espíritu. El sentido de esta inserción del espíritu en la vida es la persona (2002: 224).

En vista de lo anterior, el filósofo alemán describe la guerra como la afirmación de los impulsos vitales de las personas singulares independientes, espirituales e individuales concentradas en una persona colectiva, independiente, espiritual e individual, conocida como "Estado" (Staat). De acuerdo con Albert Márquez, dado su carácter esencialmente social, la persona en Scheler se concibe necesariamente como miembro de diversas unidades sociales, esto es, "tipos

selección natural, a fin de señalar su relación con la facultad de selección del hombre; pero la expresión frecuénteme usada por míster Herbert Spencer de la supervivencia de los más adecuados es más exacta y es algunas veces igualmente conveniente". Darwin, Charles, El origen de las especies (Tomos I y II), UNAM, México, 1997: 151. 
ideales que se presentan en la vida colectiva real en diversas 'mezclas' (Vermischungen)" (2004: 113), distinguiendo cuatro formas principales: "masa" (Masse), "comunidad vital" (Lebensgetneinschaft), "sociedad" (Gesellschaft) y "persona colectiva" (Gesamtperson), siendo esta última la unidad social de valor supremo:

Sólo la persona espiritual colectiva en forma de Iglesia, nación, círculo cultural, Estado, se eleva por estos dos tipos especiales de asociaciones: por encima de la comunidad vital y de la sociedad. Pues sólo en estas formaciones sociales el espíritu y los bienes autónomos realizados colectivamente por el grupo adquieren la máxima eficacia de la formación humana (Scheler, 1961: 24).

Así, a los ojos de Scheler, la Primera Guerra Mundial constituyó la evidencia más palpable de la controversia del poderío y la voluntad sostenida entre una multitud de Estados (Alemania, Inglaterra, Rusia y los otros países de Asia), cuya finalidad última -más allá de las intenciones subjetivas de los beligerantes- fue el máximo dominio espiritual sobre la Tierra.

Es cierto que no puede concebirse la guerra sin la presencia de medios físicos violentos. No obstante, para el muniqués es sólo una manifestación, medida y señal de las energías de la voluntad que entran en conflicto; mas nunca, su núcleo: "brota del espíritu y para el espíritu es la guerra en su núcleo más profundo" (Scheler, 1915: 10). Asimismo, la guerra no ha de equipararse con una cruel e insensata matanza. En dicho acto, la voluntad niega la existencia de una persona individual en tanto que persona, arrebatándole, de cierto modo, su ser y su dignidad. Pero en la guerra (al menos en la guerra que está concibiendo Scheler) nada hay de esto, pues se trata de una lucha no de individuos, sino de Estados en donde la violencia y la muerte son vistas con una actitud de amor y gran respeto ${ }^{8}$.

\footnotetext{
${ }^{8}$ Es aquí donde surge la clásica recriminación de José Ortega y Gasset: "enoja a Scheler que no se reconozca en el Estado una persona real, tan real como el individuo. ¿No debe enojar más que Scheler rebaje, dentro de la enorme persona Estado, la persona individual al papel de una imagen, de una sensación, de un instinto?" Ortega y Gasset, "El genio de la guerra y la guerra alemana", op. cit., p. 198. Al respecto, se recomienda revisar el trabajo de Ricardo Gibu, "En torno a la esencia del poder: Un estudio comparativo entre Max Scheler y José Ortega y Gasset" en Franciscanum 163, Vol. LVII (2015), pp. 125153 , en donde demuestra que en modo alguno Scheler ha suprimido la singularidad del yo por la personalidad espiritual colectiva del Estado, tal y como fue el sentir del filósofo madrileño.
} 
Igualmente, la guerra tuvo para Scheler un valor eminentemente positivo para la creación cultural. El oriundo de Múnich sostiene que, desde un aspecto histórico, la cultura no alcanza su perfeccionamiento a través de la simple lucha por el alimento, la reproducción y el aseguramiento de la existencia; tampoco lo hace a la manera de la sociedad (Scheler piensa aquí particularmente en las corrientes ideológicas específicamente inglesas, a saber, el utilitarismo y el liberalismo), esto es, por medio de una unión artificial de individuos que, buscando el mayor nivel de vida, se convierte en una inclusión de los sujetos individuales dentro de ciertas clases específicas de una red de clase de algún modo estructurada; ni por una causalidad orgánica, propia de las comunidades vitales, cuyo acrecentamiento se entiende como una derivación de la conservación mediante la herencia (la sangre, la tradición, las costumbres, el vestido). Antes bien, el crecimiento cultural se da en "aquella tendencia primaria al engrandecimiento a través de la expansión del entorno y la formación orgánica de la guerra como un recurso intencional de distribución del poder entre las naciones" (Scheler, 1915: 53). La guerra es, pues, una fuente de renovación cultural. Gracias a ella, según el muniqués, no sólo fue posible la conquista y el crecimiento demográfico en muchas partes del mundo, sino también el desarrollo de la tecnología, las ciencias, las artes y la filosofía (Scheler menciona el ejemplo del Renacimiento italiano y del clasicismo alemán, dos periodos culturales con trasfondo bélico) (Safranski, 2010: 125), pues provoca que las dotes existentes en el hombre vuelvan a sumergirse profundamente en las fuentes creadoras del espíritu nacional y del personal de una manera tal como para recordarle quién es y para qué sirve. De ahí que Scheler nombrara a la guerra como: "el principio dinámico de la historia por excelencia" (Scheler, 1915: 17). En contraste, es la paz su movimiento opuesto: "la paz es sólo el principio estático de la historia, mientras que en toda guerra se verifica un retorno a la originalidad creadora de donde nació el Estado" (Ibíd.).

En correspondencia con lo anterior, Scheler estimó a la guerra como algo mucho más valioso que la paz. Empero, resulta importante aclarar que el filósofo no desestimó su papel, el cual también era de vital importancia, ya que permitía la adaptación al sistema dinámico de poderes determinado por la guerra precedente: "en tiempos de paz no hay una reflexión consciente sobre quién o qué somos como cultura, persistiendo la estabilidad en su forma actual de desarrollo" 
(Davis, 2012: 133, trad. propia). El problema para Scheler radica más en las intenciones de las teorías pacifistas que, a su consideración, parten de una concepción estática, y por tanto, falsa de la historia, misma que habría sido impulsada a raíz de tres ideas elucubradas en el liberalismo inglés: "la doctrina contractual del Estado, la doctrina de la armonía natural de los intereses, y la negación (mecanicista) de agentes centrales que gobiernan e intervienen en el juego de fuerzas de cualesquiera unidades elementales (mundo, alma, Estado)" (Scheler, 1915: 29-30). Estas tres tesis, de acuerdo con Scheler, provocaron que autores como Spencer presentaran una ley de fases para el conjunto de la humanidad conforme la cual está haya de avanzar hacia la paz (del status al contractus, de una época teológico-belicosa a una época industrial-positivista y pacífica) (Scheler, 2000: 153), y, por ende, también la creación de un pacifismo que demoniza toda acción bélica al mismo tiempo que busca permanentemente la paz. Querer esto sería, para el filósofo alemán, reprimir la expresión natural de la vida, su despliegue, expansión y autodefensa, hecho que daría lugar a un profundo resentimiento colectivo y a una decadencia moral.

Finalmente, Scheler mostró en su disertación que la guerra no es lo contrario de, sino una expresión del ser de Dios, dándole así a este fenómeno un significado sagrado. En efecto, el propósito fundamental de toda acción bélica es, de acuerdo con el muniqués: "la formación y extensión de algunas de las muchas formas de verdaderas unidades de amor (Liebeseinheiten), como «el pueblo», la «nación», etc., que son lo opuesto a aquellas sociedades fundadas fáctica o contractualmente" (Scheler, 1915: 10). Inspirado en la concepción paulina del corpus christianum como corpus Christi en donde están implicados el valor propio de la persona, la idea del amor y la idea de salvación de todos sus miembros, Scheler vislumbra el concepto de "nación" (Nation) como una persona colectiva completa. Lo es a diferencia del Estado, cuya naturaleza asemeja a la de una "cabeza de Jano" (Januskopfe), una realidad dual en donde se mezcla la naturaleza y el espíritu. La nación, nos dice Scheler, es una persona colectiva espiritual fundada en una suma de voluntades que libremente deciden unir sus destinos en un proyecto común guiadas por el amor, cuya labor estriba en "conducir las fuerzas impulsivas del pueblo en orden a la realización de su misión individual" (Albert, 2004: 118). Sólo aquí se escucha el llamado de la justicia como una tarea personal y, en última instancia, como la voluntad de sacrificar la propia voluntad de 
vivir. Entonces, es el genio de la guerra "el mayor asistente de la luz, santa y hermosa del genio del amor" (Scheler, 1915: 280), un retorno al profundo y universal don de Dios.

\section{EL VALOR DE LA PAZ}

Contrario a lo que se pronosticaba, la Primera Guerra Mundial no fue una guerra corta al estilo de las campañas napoleónicas decimonónicas, que tuvieron "una batalla decisiva, un número limitado de bajas y un final rápido de las hostilidades" (Fulbrook, 2009: 173), sino una guerra de cincuenta y un meses que desplegó un nivel de violencia y brutalidad hasta entonces desconocido en Europa, que padeció en sus propias carnes las consecuencias del fenómeno bélico en plena era industrial con la introducción de las armas químicas, las ametralladoras y la artillería de grueso calibre. Así, el entusiasmo y las esperanzas, que se habían depositado cuando estalló "la guerra de las ilusiones" (como la llamaría Fritz Fischer), aquella que iba a acabar con todas las guerras, la guerra que traería la paz, la "guerra buena", se extinguieron al interior de las trincheras junto con las vidas de poco más de diez millones de personas.

Max Scheler, aunque presenció una notable mejora en sus perspectivas profesionales durante los años en que se suscitó el conflicto, debido al éxito obtenido con El genio de la guerra y la guerra alemana, comenzó a sospechar e indignarse con el conflicto, y, tras una estancia en la abadía benedictina de Beuron (lugar que ejerció un atractivo singular sobre otros fenomenólogos como Edith Stein y Martin Heidegger) en 1916 (Ferrer, 2008: 383), se generó en él un "despertar religioso" y con éste, un segundo giro dentro de su pensamiento que lo obligará a replantearse - aunque no de manera inmediata - su posicionamiento político inicial. A partir de ese mismo año, Scheler se concentró en la redacción de una serie de trabajos, los cuales fueron publicados en las revistas Summa ${ }^{9}$ y Hochland ${ }^{10}$ (esta última de orientación católica), que pretendían, por una parte,

\footnotetext{
${ }^{9}$ Los títulos de los mismos son Reue und Wiedergeburt (Arrepentimiento y nuevo nacimiento), Vom Wesen der Philosophie und der moralischen Bedingung des philosophischen Erkennens (La esencia de la filosofía y la condición moral del conocer filosófico), ambos publicados en 1917.

${ }^{10} \mathrm{~A}$ estas publicaciones pertenecen, sobre todo: Soziologische Neuorientierung und die Aufgabe der deutschen Katholiken nach dem Kriege (La nueva orientación sociológica y la tarea de los católicos alemanes después de la guerra) (1915/16), Probleme der Religion. Zur religiösen Erneuerung (Problemas de
} 
mostrar que el valor de la Gran Guerra en Europa fue el de poner en evidencia la profunda crisis intelectual y espiritual en la que se encontraba este continente desde hace tiempo:

La guerra, esa mentira y engaño interior, hace largo tiempo ya no existe por el veneno del nacionalismo y el subjetivismo, poniendo al descubierto una comunidad cultural europea carcomida por el relativismo y el capitalismo, y ha traído la luz del día, (...) por ello, idebemos incluso agradecerle a la guerra! (Scheler, 1921: 228, trad. propia).

Del mismo modo, el filósofo muniqués no desistió en su empresa por averiguar el sentido del fenómeno bélico, ahora concebido bajo la luz del catolicismo, como: "la primera experiencia global de la humanidad en la que ésta es llamada hacia la conversión interior y el arrepentimiento" (Wolfhart, 1998, trad. propia). Ténganse en cuenta que Scheler (1921) no reconoce una responsabilidad total del pueblo alemán en la guerra, pues, a su parecer, esta se encuentra inseparablemente entrelazada e intrincada con el resto de los pueblos de Europa y aún en el mundo entero, tal como lo expresó en su conferencia pronunciada en 1917 De la reconstrucción cultural de Europa:

En primer lugar, por lo tanto, debe venir el reconocimiento de que a fin de cuentas sólo hay una respuesta a la pregunta, ¿Quién o qué nación es responsable por esta guerra? La respuesta es usted, el que realiza la pregunta por lo que hizo o lo que dejo de hacer (1917: 224, trad. propia).

Así, Alemania y Europa en su conjunto serían capaces de comenzar un renacimiento cultural y social, si y sólo sí, eran capaces de asumir esta "culpa en común" (Gemeinschuld), lo que provocaría el despertamiento del "gran pathos del posible perdón recíproco, del posible arrepentimiento colectivo, de la penitencia colectiva por esta culpa (de la voluntad de reconciliación que hoy todavía se estremece, como avergonzada)" (Scheler, 2007: 56). Por otra parte, Scheler buscó la despolitización, así como el despertar espiritual de las fuerzas religiosas

la religión. Para la renovación religiosa) (1918), Die christliche Liebesidee und die gegenwärtige Welt (La idea del amor cristiano y el mundo presente) (1917), Vom kulturellen Wiederaufbau Europas (De la reconstrucción cultural de Europa) (1917/18), así como muchas críticas y recensiones. 
y culturales del catolicismo, pues en él veía el motor para la renovación de Europa tras la guerra; no mediante la creación de un nuevo orden político o económico, sino a través de una auténtica "comunidad espiritual" (Gemeinschaft).

El esfuerzo del filósofo muniqués para rehabilitar a la Iglesia Católica por medio de la asignación de esta nueva e importante tarea, le valió que el Ministro Alemán de Asuntos Exteriores lo designara como "Embajador de la buena voluntad", realizando misiones diplomáticas desde el verano de 1917 y hasta octubre de 1918, dentro de los círculos católicos, considerados importantes, de Berna, Ginebra, Viena y La Haya. Si bien, tales misiones no tuvieron una importancia decisiva, demuestran su mayor acercamiento espiritual con la Iglesia, al punto de que "se le veía y reconocía ampliamente como representante del catolicismo alemán" (Coreth, Neidl y Pfligersdorffer, 1997: 89).

Durante ese tiempo, Scheler continuó trabajando dentro del paradigma político, ocupado en los problemas sociales actuales, tales como el capitalismo, el socialismo, el militarismo a través del movimiento feminista y la liberación sexual. Sin embargo, él tuvo relativamente poco qué decir sobre el genio de la guerra hasta el invierno de 1926/27, cuando el Ministerio Alemán de las Fuerzas Armadas lo invitó para dirigir unas palabras hacía el joven cuerpo de oficiales, el cual, en palabras de Smith: "se encontraban profundamente divididos en dos bandos en los temas de la paz y la guerra" (1974: 84, trad. propia). Ciertamente, el castigo de la Gran Guerra no fue, al parecer, lo suficientemente ejemplarizante pues a casi diez años del conflicto ya existía la amenaza, cada vez mayor, de una segunda y mucho más violenta, guerra mundial. El tratado de Versalles, firmado en julio de 1919, había levantado un fuerte resentimiento en el pueblo alemán, dado que, por un lado, redujo considerablemente sus fronteras y su ejército y, por el otro, le hizo ser el único responsable moral por el desencadenamiento del conflicto, con lo que se le impuso el pago de las respectivas indemnizaciones debido a los daños que sufrieron los aliados (aproximadamente treinta y tres millones de dólares), provocando con este hecho un considerable aumento del gasto público. Además, la República de Weimar -el primer sistema democrático que conoció Alemania- estructuralmente débil, parecía ser incapaz de garantizar "la conflictiva existencia de las diferentes clases y grupos de una sociedad civil por debajo del umbral del golpe de Estado y la guerra civil y sin el vínculo conciliador de la simbolización unitaria del pueblo como nación" (Rödel, Ülrich, 
Frankenberg y Dubiel, 1997). No es de sorprender, entonces, el surgimiento en toda Alemania (y también en el resto de Europa) de movimientos extremistas que proponían soluciones simples basadas en la ideología y el poder, tensando aún más la práctica democrática. Ante esto, era cuestión de tiempo para que Alemania se volviera a reafirmar, pero el asunto era: ¿cuál Alemania?, ¿la de la pluma o la de la espada?

Scheler, consciente de lo anterior, para 1926 ya había dado otra conferencia a las Fuerzas Armadas titulada Política y Moral (1990), en donde aborda la profunda separación entre "poder" (Macht) y "espíritu" (Geist) que imperaba en el pueblo alemán y que, de acuerdo con él, obstaculizaba el paso hacia una forma democrática de gobierno. Un año después, presenta su disertación La idea de la paz perpetua y el pacifismo, la cual concibe como la segunda parte de aquel trabajo sobre política y moral ${ }^{11}$. Ahora bien, Scheler pretende hablar aquí sobre la idea eterna de la paz, pero no como un católico (se había separado intelectualmente de la Iglesia desde 1924), sino como un hombre comprometido moralmente a advertir sobre los catastróficos peligros que se encontraban al interior de la crisis cultural por la que atravesaba Europa en aquel momento y cuyos efectos apenas se estaban conociendo. De igual modo, el filósofo, que no se había olvidado de su disertación sobre el genio de la guerra, sintió la obligación de revertir su posicionamiento bélico inicial, estableciendo como tesis central de su ensayo que "la guerra y las formas de vida militares y belicosas no son inherentes en absoluto a la «naturaleza humana». La paz perpetua es absolutamente posible en la historia de la humanidad" (Scheler, 2000: 139).

Efectivamente, como si de un ejercicio de catarsis se tratara, Scheler emprende una crítica al militarismo ( $y$ con ello a toda su temprana defensa de la guerra), cuyos postulados él mismo reduce en cuatro puntos fundamentales: 1. La guerra es algo "natural" al ser humano, pues potencia alguna de sus cualidades y virtudes más nobles; 2 . La guerra fortalece a los pueblos; 3 . La guerra favorece el renacimiento y resurrección de la cultura; y 4. La guerra crea unidad.

${ }^{11}$ Scheler tenía planeado dictar la misma conferencia un año después, tras su asignación como profesor de filosofía en la Universidad de Frankfurt. Sin embargo, muere poco después de su presentación ante el Ministerio de Defensa, el 19 de mayo de 1928, siendo este tema "su última preocupación filosófica" (Smith, F. J., 1974: 85). 
Sobre el primer punto, Scheler afirma que, si bien la guerra puede brindar la ocasión para el surgimiento de ciertas virtudes, sobre todo las heroicas, como el sacrificio y el valor, no es el concepto del ethos guerrero el modelo supremo del hombre, sino el bondadoso, el santo, el espíritu noble, desde el cual se desarrolla un "heroísmo de la paz" (Friedenheroismus), que es mucho mayor y más profundo que todo "heroísmo fundado en la guerra" (Kriegsheroismus): "el heroísmo de los defensores de la no-violencia, el heroísmo de Buda, el heroísmo de la vida monástica budista y cristiana, el heroísmo de los mártires cristianos y de toda clase de mártires, etc." (Scheler, 2000: 143).

Acerca del segundo punto, Scheler considera como un absurdo el atavío darwinista de la mentalidad militarista que contempla a la guerra y a las formas de vida militares como mecanismos para el fortalecimiento de las naciones. De acuerdo con el muniqués, la llamada "lucha por la existencia" lejos de vigorizar a un pueblo, lo debilita porque: "la guerra aparta de la reproducción a las generaciones más jóvenes y vigorosas y nos deja a los biológicamente menos aptos" (Scheler, 2000: 145). Asimismo, el filósofo establece que no es la guerra, sino el fomento del deporte, la lucha contra la degeneración de las sociedades y las razas, el desarrollo de una enérgica política social en relación con la vivienda, el asentamiento de la población, las condiciones de trabajo y la jornada laboral, así como muchas otras disposiciones, lo que fortalece a un pueblo.

En el tercer punto, reconoce que la guerra es causa eficiente para el nacimiento de la cultura, pero en ningún modo es una causa para su planificación y desarrollo. De acuerdo con el filósofo, el crecimiento cultural no tiene lugar en el regreso o el despertamiento de algún origen olvidado, tal y como lo difundieron los portadores del nacionalismo en Alemania, dado que "en la historia de toda civilización y de toda cultura no sólo se produce un cambio de fines, sino también un cambio de orígenes" (Scheler, 2000: 146). Cierto que el espíritu, así como la vida, goza de su propio curso independiente de desarrollo, el cual pasa a través de los actos individuales y colectivos de un pueblo. Estos actos asumen el estilo original de una cultura y, creativamente, la transforman en un estilo particular de persona o generación. De ahí la razón por la que, según nuestro autor, las guerras nacionales modernas no han hecho otra cosa que destruir la cultura, pues "el origen es siempre ya presente. No es una cuestión de sacudirnos a nosotros mismos de algún letargo cultural, sino de reconocer que las acciones 
presentes de uno son responsables de la evolución futura de una cultura" (Davis, 2012: 141).

Finalmente, Scheler admite que la idea de la guerra como un proceso de unificación de los pueblos contenida en el último punto es, de hecho, el argumento más fuerte que puede aducirse en favor del valor de la guerra. El mito que describe que los hombres fueron llamados a afrontar un destino común en la guerra, no sólo se convirtió en el arma propagandística más usada durante la Gran Guerra, sino también fue el tema dominante de los escritos de Scheler en aquel tiempo. Ahora, el filósofo considera que esta idea "ha de tomarse en su relatividad histórica y bajo considerables reservas; y por supuesto no se puede pretender que sea válida para todo futuro" (Scheler, 2000: 147). En efecto, el oriundo de Múnich no niega que la Guerra haya podido coadyuvar en la construcción de las grandes unidades culturales, siendo éste, de hecho, el camino escogido por el mundo occidental. Sin embargo, no es ésta la única forma. Scheler evoca aquí a las poderosas naciones orientales (China, India y Japón), cuyas unificaciones se dieron como consecuencia de la ampliación de la familia extensa y la cooperación; mostrando así que la cultura tiene su propia fuerza unificadora, una fuerza que construye un vínculo mucho más fuerte y funda unidades colectivas más profundas. Por otro lado, el muniqués sostiene que la noción típicamente occidental que promueve la unión de los pueblos a través de la guerra, ciertamente funciona, siempre y cuando: "haya nacido de un deseo preexistente de unidad nacido de una cooperación simpatética, al que la guerra sólo viene a asistir" (Scheler, 2000: 148) y cuando detrás de los pueblos vencedores existen también ideas, así como un legado cultural que difundir. De manera que, aquellas unificaciones basadas únicamente en la violencia y en la guerra, no entendida como un medio para la consecución de fines políticos, sino como un fin en sí misma, son siempre de corta duración. Bástese con recordar la admirable, aunque fugaz, unidad del sacrificio, la fraternidad, la creencia y la certeza en la victoria que detentó entusiastamente el pueblo alemán al inicio del conflicto y que se desmoronaron con la misma rapidez con que la guerra las forjó.

Scheler concluye su refutación hacia el militarismo aseverando que la guerra ni es la expresión del dinamismo de la vida, si el afán de poder puede expresarse en relación con los dioses, con los propios procesos vitales (ascetismo), con otros hombres (impulso de dominio) y en relación con la naturaleza (primero con la 
orgánica y luego con la inorgánica en el trabajo y la técnica); ni el héroe es comprendido únicamente en el ámbito de un conflicto bélico. Esta resolución, de acuerdo con Smith, es respaldada por su concepción del ordo amoris: "la estructura humana de amar es más característico a la 'naturaleza' del hombre que cualquier ordo belli; no es la beligerancia sino el amor la estructura básica experiencial del hombre" (1974: 86). Esto explicaría por qué en la humanidad, aún en medio de las catástrofes llenas de horror y odio, resuena una y otra vez el clamor por la reconciliación de los pueblos y la paz en la Tierra: "el hombre tiende a la paz como un telos, no en el sentido de un mero objetivo político con toda la estrechez que implica, sino como un equilibrio experiencial también aplicable a las situaciones políticas" (Ibíd.). Pensar lo contrario, es entendido por Scheler como una aberración del amor. Así, el ethos militarista que impulsa un "ideal heroico" basado en la agresividad no sería más que la falsificación y la distorsión de los valores de amor como producto del resentimiento.

Otro de los objetivos que Scheler planteó en su escrito consiste en dictaminar si la humanidad actual ha alcanzado ya una situación en la que pueden evitarse futuras guerras a través de realización efectiva de la paz perpetua. Si bien reconoce - aunque con ciertas reservas - la evidencia de una tendencia hacia la ejecución paulatina y progresiva de esta idea, su respuesta resulta, no obstante, negativa: "el camino hacia la paz perpetua, que nosotros reconocemos como dirección fundamental de la historia universal, es algo todavía más y más lejano en el tiempo, algo que ni siquiera puede barruntarse" (Scheler, 2000: 161). Aunque la aciaga experiencia de la guerra parecía haber despertado la conciencia adormecida de la mayor parte de las naciones europeas que ahora demandaban la consecución de una paz duradera mediante el establecimiento de acuerdos económicos y políticos, existían aún demasiados problemas bajo el cielo europeo, los cuales, según el muniqués, habrían derivado de la contención y represión de afectos e impulsos no sublimados que la paz trajo consigo, sobre todo si pensamos en la parcialidad con la que fue dispuesto el Tratado de Versalles (que además de crear disensiones entre los vencedores, provocó el resentimiento y la ira de los vencidos a causa de su dureza), y que también originaron nuevas tendencias a la guerra o a la revolución: "tendencias que, ciertamente no siempre conducen a guerras reales, pero que hay que tener en cuenta en el estallido de éstas, 
en tanto que causas psíquicas subconscientes de naturaleza rítmica" (Scheler, 2000: 158).

Con todo, lejos de entregarse al pesimismo, el discurso del muniqués se torna desafiante y rebozado de esperanza: "la paz perpetua es un «ideal», no un sueño como Immanuel Kant supo ver, y un ideal bello y bueno" (Scheler, 2000: 150). Para Scheler, la paz es un ideal ejemplar, un paradigma que espera ser encarnado en la historia de la humanidad, lo cual será posible a partir de un cambio de dirección del impulso de poder, y esto sólo podrá realizarse, a su vez, en la medida en que los hombres se den cuenta de que están llamados "desde lo alto" a desear y realizar la paz en la tierra. Este llamado emerge de aquella orientación originaria del hombre, su ordo amoris. Ricardo Gibu, a propósito, describe de manera sucinta pero atinada, el meollo de esta cuestión:

Sólo desde este movimiento es posible reconocerse distinto a todo el orden de lo vivo y al mismo tiempo capaz de trascender todas las cosas incluyéndose a sí en dirección al principio que hace posible esta trascendencia, esto es, la divinidad. Sólo en ese momento el hombre es capaz de entrar en sí mismo y de reconocerse sujeto de acciones libres. La libertad humana y, por tanto, el poder humano lejos de ceñirse a la lógica de medios y fines fundada en la percepción de cosas y nexos particulares, tiene ante sí la totalidad de las cosas a través del fenómeno "mundo". Además, en virtud del acto religioso que le permite coejecutar la intención de lo divino, tiene ante sí el fenómeno "Humanidad". En la posibilidad de amar el mundo y amar la humanidad se sintetiza el poder de la persona. La producción de bienes a través de tales actos constituye una verdadera transformación del mundo real y un acrecentamiento efectivo de su valor (2015: 149).

Así, desde la perspectiva del amor, el ideal de la paz se concibe no como una abstracción intelectual o una idea utópica, sino más bien como su proyección lógica. De modo contrario, cuando la negación o el opuesto de los valores más profundos, es decir, el odio, toman forma en el mundo, estamos llamados a la destrucción:

La humanidad se convierte cada vez más, en parte gracias a la guerra, en una humanidad en que las tensiones de los contrarios que son la sangre y la cultura alcanzan un equilibrio relativo. La guerra misma arrastra a partes cada vez mayores de la humanidad hacia uno y el mismo destino (Scheler, 2000: 157). 
Sí, la paz es posible, empero, no es realista pensar que se puede aplicar de forma proactiva: "sólo podemos dirigirla y conducirla, no producirla y crearla" (Scheler, 2000: 162), y dado que éstas no constituyen fases reales en el camino hacia la paz perpetua, sino que constituyen una creencia metafísica, es decir: "son tan sólo leyes del cambio de dirección de una curva cuyo comienzo y final nos es completamente desconocido" (Scheler, 2000: 157), las tensiones políticas, los episodios de violencia y las guerras continuarán. Sobre esto, Davis nos dice que "debido a que no vivimos en un mundo que no está totalmente espiritualizado, estamos llamados a emprender una acción militar" (Davis, 2012: 147). Sin embargo, esta acción siempre lleva consigo una llamada adicional para aceptar la responsabilidad de las condiciones del mundo actual y tomar medidas con el fin de cambiarlo: "la guerra no es una señal de que el ser humano ha caído y que este mundo está destinado a la violencia, sino más bien una señal de que este mundo no es todavía lo que puede y debe ser" (Davis, 2012: 147-148). En suma, la idea de la paz perpetua en Scheler no implica la ingenua creencia de una absoluta ausencia de conflictos entre las personas, antes bien, se trata de una idea seminal que invita a cada hombre a asumir su responsabilidad no sólo por lo que ha de venir, sino por lo que también ha sido: "la paz revela su genio al negarse que el pasado determine el futuro y demostrando que el amor persiste obstinadamente, incluso en el más horrible de los tiempos" (Davis, ib.: 148-149). Asimismo, el ideal de la paz mueve a los seres humanos a actuar, a tomar acciones hacia la edificación de un mundo en donde se pueda vivir, trabajar, progresar, discrepar y crecer como individuos y sociedad.

Curiosamente, Scheler ya había llegado a esa resolución, incluso antes de que la Gran Guerra tuviese lugar, en el Resentimiento en la moral:

Exigencias como las de paz mundial, supresión de la lucha social de clases por el poder político, son totalmente ajenas a su predicación religioso-moral. La paz en la tierra que Él predica es una última tranquilidad beata, que debe iluminar, como desde arriba, toda esa lucha y contienda, a través de cuyas formas históricas cambiantes se desarrollan la vida y las sociedades humanas; de modo que los fines por los cuales se lucha no sean nunca considerados como últimos y definitivos, sino que haya siempre en el fondo de las personas un lugar sagrado donde reinen la paz, el amor y el perdón, en medio de la lucha y la contienda. Pero esto no quiere decir que deban cesar esas luchas y morir los impulsos que llevan a ellas. (...) Lo valioso no es, pues, 
la anulación o la moderación de los impulsos vengativos, de los instintos ambiciosos de dominio y de mando, sino el libre sacrificio de estos impulsos e instintos, que son reconocidos como necesarios en todo ser vivo normal, $y$ de las acciones y expresiones correspondientes. $Y$ dicho sacrificio ha de hacerse en aras del acto más valioso del perdón y del sufrimiento (Scheler, 1938: 127-128).

Lograr esta paz constructiva nos puede llevar mucho tiempo; preservarla, toda la vida.

\section{BIBLIOGRAFÍA}

ALBERT, M. (2004), Derecho y valor: una filosofía jurídica fenomenológica. Madrid: Encuentro.

Bermes, C., Henckmann, W., Leonardy, H. (1998), Denken des Ursprungs Ursprung des Denkens. Schelers Philosophie und ihre Anfänge en Jena. Würzburg: Königshausen und Neumann.

Coreth, E., Neidl, W. M. y Pfligersdorffer, G. (1997), Filosofía cristiana en el pensamiento católico de los siglos XIX y XX, Vol. 1. Madrid: Encuentro.

DARWIN, C. (1997), El origen de las especies (Tomos I y II). México: UNAM.

DAvis, Z. (2012), "The Values of War and Peace: Max Scheler's Political Transformations". Symposium, 16(2), 128-149.

FERRER, U. (2008), Para comprender a Edith Stein. Madrid: Palabra.

FULBROOK, M. (2009), Historia de Alemania. Madrid: Akal.

GiBu, R. (2015), "En torno a la esencia del poder: Un estudio comparativo entre Max Scheler y José Ortega y Gasset". Franciscanum. 57(163), 125-153.

NietzsCHE, F. (1995), La genealogía de la moral. Valencia: Universitat de Valencia.

ORTEGA Y GASSET, J. (1963), "El genio de la guerra y la guerra alemana", en Obras completas, Tomo II: El espectador (1916-1934), Madrid: Revista de Occidente.

Rödel, Ü., Frankenber, G. Y Dubiel, H. (1997), La cuestión democrática. Madrid: Huerga y Fierro.

SAFRANSki, R. (2010), El mal o el drama de la libertad. México: Tusquets. 
SCHELER, M. (1915), Der Genius des Krieges und der Deutsche Krieg. Leipzig: Weisse Bücher.

-, "Vom kulturellen Wiederaufbau Europas", en Vom Ewigen im Menschen. Leipzig: Der Neue Geist.

-, (1938), El resentimiento en la moral. Buenos Aires: Espasa-Calpe.

-, (1957), Vorbilder und Führer en Gesammelte Werke, Bd. X: Schriften aus dem Nachlass. Bd. 1: Zur Ethik und Erkenntnislehre. Bern: FranckeBouvier Verlag.

(1961), El santo, el genio, el héroe. Buenos Aires: Nova.

(1990), "Politik und Moral" en Gesammelte Werke, Bd. XIII: Schriften aus dem Nachlass. Bd. 4 Philosophie und Geschichte. Bern: Frankle Verlag

-, (2000), El puesto del hombre en el cosmos. La idea de la la paz perpetua y el pacifismo. Barcelona: Alba.

-, (2007), De lo eterno en el hombre. Madrid: Encuentro.

SмIтH, F. J. (1974), "Peace and pacifism", en M. S. Frings, (ed.), Max Scheler (1874-1928), Netherlands: Centennial Essays, Springer

SuANCES, M. (2002), "Concepto y valor de la vida en Max Scheler". En A. Domínguez, (Coord.), Vida, pasión y razón en grandes filósofos. Cuenca: Universidad de la Castilla-La Mancha.

WolfHART, H. (1998), Max Scheler. München: Beck. 